\title{
Algorithm of vehicle emergency evacuation in urban large-scale activ- ities
}

\author{
D WANG \& J.Y. LI,W.Y. ZHANG,F.F. LI \\ Shenyang University, Shenyang, China \\ Shenyang University, Shenyang, China \\ Ji Lin Vocational and Institute of Technology, Changchun, China
}

\begin{abstract}
KEYWORD: Large-scale activities; Emergency evacuation
ABSTRACT: This article studies the problem of vehicle emergency evacuation in urban large-scale activities. Genetic algorithm and ant colony genetic algorithm are applied to the vehicle emergency evacuation separately. Finally, we choose the Shenyang Olympic Sports Center as an example, and the simulation results verify the feasibility of vehicle emergency evacuation optimization algorithm in this paper.
\end{abstract}

\section{INTRODUCTION}

In recent years, with the continuously development of economic construction and the gradually improvement of people's living standards, More and more large-scale activities are held in the cities. It's a huge challenge for those cities which are in a state of traffic tension. There will be a large number of people and traffic flows distribute in a short period of time during the large-scale activities. If some unexpected events occurred at this time, it will have an immeasurable impact on urban traffic. At this point, the traffic emergency evacuation is particularly important. It can not only help traffic managers to evacuate the traffic flow in a short time quickly and effectively, but also provide protection for people's lives and property. The reasonable plans of traffic emergency evacuation, not only improve the ability to deal with large events, but also ensure the safety and order of the traffic emergency evacuation process. It also has a positive effect on relieving traffic pressure and reducing the occurrence of secondary events. The ultimate goal of this paper is to study how to make effective and reasonable traffic emergency evacuation plans.

This paper takes the urban traffic emergency evacuation as the research object. First of all, we introduce the traffic emergency evacuation models at home and abroad. And then, we plan for the road networks, which surrounding area of the site of large-scale activities on the basis of analyzing the traffic flow, and its characteristics under the condition of emergency evacuation. Based on the investigation of the field data and references, the network model for the selection of the evacuation network is established. We choose Shenyang Olympic Sports Center as an example. It is simulated and analyzed to verify the feasibility of the algorithm.

\section{VEHICLE EMERGENCY EVACUATION MODEL}

The best purpose of the vehicle emergency evacuation is to evacuate all vehicles in the shortest time. In this process, the shortest path strategy seems to be the optimal evacuation plan. Since in the same evacuation speed case, the shorter distance, the shorter time to reach the destination. If all evacuated objects choose the shortest path to its destination, it will cause congestion in some way, so that the traffic flow will occur uneven distribution during the evacuation. Therefore, in order to avoid the drawbacks of the above vehicle emergency evacuation model based on the shortest path, emergency evacuation vehicle model based on the shortest time is presented in this paper.

The vehicle emergency evacuation model based on the shortest time of is applicable to largescale emergency evacuation. The model is not a single evacuation object, but a combination of various factors to optimize overall by the evacuation process. It is more practical significance. The emergency evacuation model target based on the shortest time in urban large-scale activities is the 
shortest time for evacuation. By optimizing the evacuation route and reducing the residence time of vehicles, the overall purpose of the shortest evacuation time is achieved. The model can establish the dynamic evacuation plan by considering the evacuation speed and the load of the road network dynamically. The model can improve the feasibility and effectiveness of the evacuation plan.

The emergency evacuation model based on the shortest time takes into account not only the evacuation routes but also the evacuation speed. It is proposed to shorten the evacuation time by optimal control to the number of the target in each evacuation time. There are many evacuation time indexes. The evacuation time mentioned in this article refers to the over time from the first evacuation object into the evacuation network to the last evacuation object into destination.

The vehicle emergency evacuation model based on the shortest time as follows:

$$
\min T=\sum_{n=1}^{N} \sum_{i=1}^{V} \sum_{j=1}^{V} \frac{d_{i j} x_{n_{f}}}{v_{n_{j}}}
$$

S.t.

$$
\begin{aligned}
& \sum_{j=1}^{V} \sum_{n=1}^{N} x_{n_{i}}=N \\
& \sum_{n=1}^{N} \sum_{i=1}^{V} x_{n_{i}}=N_{j} \\
& \sum_{j=1}^{q} N_{j}=N \\
& \sum_{n=1}^{N} \sum_{i=1}^{V} \sum_{j=1}^{q} x_{n_{2} k_{j}}=N
\end{aligned}
$$

where $V_{n_{u}}$ is the speed of the vehicle through the road $\left(V_{i}, V_{j}\right), N$ is the total number of evacuation roads, $N_{j}$ is the number of roads to reach the ${ }^{j \text {-th }}$ destination, $V_{\text {is the total number of }}$ nodes, $q$ is the number of destinations, ${ }^{k}$ is the $\mathrm{j}$-th destination.

\section{ANT COLONY GENETIC ALGORITHM}

Since the vehicle emergency evacuation model need to consider many factors, including to constraints, complex degree, and the search difficulty for the optimal solution path. So in the design of algorithms, genetic algorithm is a preferentially considered algorithm. However, since the conventional genetic algorithm premature convergence can result in local optimum, which will affect the global optimum. And in large-scale evacuation, the search time will be extended. Therefore, for the above reasons, we consider the combination of traditional genetic algorithm and ant colony algorithm to improve the quality and efficiency of solving.

(1) Establishment of fitness function

$$
F_{i}=\left\{\begin{array}{l}
\bar{F}+k_{1} C_{1}^{N_{c}} \frac{F_{i}-\bar{F}}{F_{\text {max }}-\bar{F}} \bar{F} F_{i} \geq \bar{F} \\
\bar{F}+k_{2} C_{2}^{N_{c}} \frac{\overline{F_{i}}-F}{\bar{F}-F_{\text {max }}} \bar{F} F_{i}<\bar{F}
\end{array}\right.
$$

where $\bar{F}$ is the average fitness of all individuals in the first generation; $N_{c}$ is cyclic algebra; $k_{1}, k_{2}, C_{1}, C_{2}$ are adjusting coefficient values; $F_{i}$ is fitness function value of chromosome $i$.

(2) Iterative pheromones

Suppose each iteration of the genetic algorithm generates $K$ group path, the update mechanism.

$$
\tau_{i j}(t+1)=\rho_{G A} \cdot \tau_{i j}(t)+\left(1-\rho_{G A}\right) \cdot \Delta \tau_{i j}
$$




$$
\begin{aligned}
& \Delta \tau_{i j}=\sum_{k=1}^{m} \Delta \tau_{i j}^{k} \\
& \Delta \tau_{i j}^{k}=\left\{\begin{array}{l}
\omega / d_{i j} \\
0
\end{array}\right. \\
& \tau_{G}=\sum_{t=0}^{N_{C G A}} \tau_{i j}(t)
\end{aligned}
$$

where $\rho_{G A}$ is the residual factor $0 \leq \rho_{G A}<1 ; 1-\rho_{G A}$ is the volatile degree of pheromone; $\omega$ is the custom coefficient; $N_{C G A}$ is the number of iterations in the process of genetic algorithm.

(3) Options

Individual probability is selected as follows:

$$
P_{i}=\frac{\tau_{i}^{k} F_{i}^{\lambda}}{\sum_{i=1}^{n} \tau_{i}^{k} F_{i}^{\lambda}}
$$

where $n$ is the number of paths; $k$ is an important factor of the pheromone; $\lambda$ is an important factor of the fitness; $F_{i}$ is the fitness value of the path $i$.

(4) Selection of the crossover mutation point

We use pheromone content between node $i$ and node $j$ and its length $s$ to establish the Select mechanism as follows:

$$
s=\left\{\begin{array}{l}
S_{1}=\arg \max \left(d_{s}^{\theta} / d_{s}^{\delta}\right) \\
S_{2}, \text { random selection }
\end{array}\right.
$$

where $d_{s}$ is the length of $s ; \theta, \delta$ are the two parameters, which reflect the relative importance of the pheromone and the length of the side $s$ on the point of crossover and mutation selection.

\section{NUMERICAL SIMULATIONS}

Shenyang Olympic Sports Center has Wulihe Stadium, gymnasium, swimming pool and tennis court. Stadium provided 450 parking spaces, in which one layer Huanlang stadium parking for 238 vehicles; the northwest side of the stadium, the northeastern part of parking for 212 vehicles. The article focused on the evacuation of 450 vehicles in Wuli stadium.

Evacuation networks as shown in Figure 1:

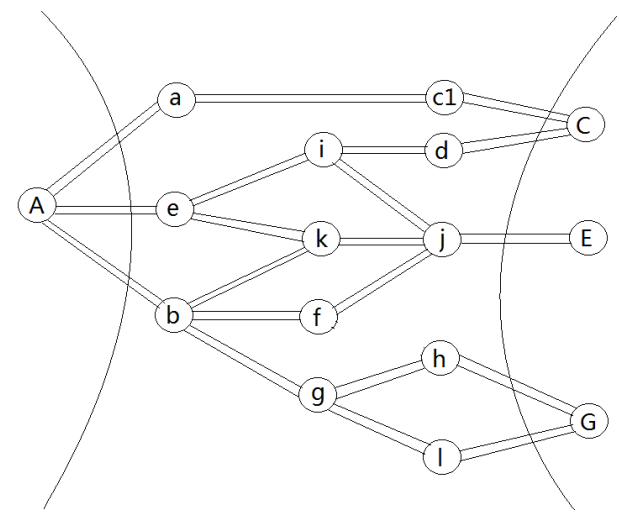

Figure1. Diagrammatic Sketch of the Evacuation Road Network

From Figure 1 can be learned, there are 12 evacuate nodes, including to three safe evacuation point. According to some information and the actual survey data, various sections are shown in Table 1 . 
Table 1 Basic Information of Road Sections

\begin{tabular}{|c|c|c|c|c|c|c|}
\hline \multicolumn{2}{|c|}{ No. Sections } & \multirow{2}{*}{$\begin{array}{l}\text { Capacity } \\
\text { veh / h }\end{array}$} & \multirow{2}{*}{$\begin{array}{l}\text { Length } \\
\text { km }\end{array}$} & \multirow[t]{2}{*}{ ULN } & \multirow{2}{*}{$\begin{array}{l}\mathrm{MS} \\
\mathrm{km} / \mathrm{h}\end{array}$} & AVAR \\
\hline & & & & & & veh / s \\
\hline 1 & A-a & 158 & 0.217 & 2 & 40 & 2 \\
\hline 2 & A-b & 140 & 0.201 & 2 & 40 & 2 \\
\hline 3 & $a-b$ & 80 & 0.103 & 2 & 40 & 2 \\
\hline 4 & b-c1 & 302 & 0.409 & 2 & 40 & 2 \\
\hline 5 & c1-C & 275 & 0.385 & 2 & 40 & 2 \\
\hline 6 & $\mathrm{~d}-\mathrm{C}$ & 265 & 0.370 & 2 & 40 & 2 \\
\hline 7 & $\mathrm{c} 1-\mathrm{d}$ & 52 & 0.075 & 2 & 40 & 2 \\
\hline 8 & d-e & 158 & 0.222 & 2 & 40 & 2 \\
\hline 9 & $\mathrm{~d}-\mathrm{i}$ & 172 & 0.258 & 2 & 40 & 2 \\
\hline 10 & A-f & 182 & 0.267 & 2 & 40 & 2 \\
\hline 11 & $f-j$ & 60 & 0.080 & 2 & 40 & 2 \\
\hline 12 & $\mathrm{j}-\mathrm{E}$ & 62 & 0.085 & 2 & 40 & 2 \\
\hline 13 & A-g & 63 & 0.088 & 2 & 40 & 2 \\
\hline 14 & g-k & 85 & 0.123 & 2 & 40 & 2 \\
\hline 15 & $\mathrm{f}-\mathrm{g}$ & 172 & 0.235 & 2 & 40 & 2 \\
\hline 16 & $\mathrm{~g}-\mathrm{h}$ & 180 & 0.240 & 2 & 40 & 2 \\
\hline 17 & $\mathrm{j}-\mathrm{k}$ & 238 & 0.398 & 2 & 40 & 2 \\
\hline 18 & $\mathrm{k}-\mathrm{h}$ & 225 & 0.370 & 2 & 40 & 2 \\
\hline 19 & h-G & 175 & 0.242 & 2 & 40 & 2 \\
\hline 20 & $1-G$ & 150 & 0.203 & 2 & 40 & 2 \\
\hline
\end{tabular}

ULN : Unidirectional lane number.

MS: Max speed.

AVAR: Average vehicle arrival rate.

Using the basic information of each path, we separately use separate genetic algorithm and hybrid ant colony genetic algorithm, the optimization path and the evacuation time as shown in table 2 and 3.

Table 2 Optimal Evacuation Routes of Genetic Algorithm

\begin{tabular}{|c|c|c|c|c|}
\hline \multirow[t]{2}{*}{ TSAEP } & \multirow[t]{2}{*}{ ER } & \multirow{2}{*}{$\begin{array}{l}\text { PL } \\
\mathrm{km}\end{array}$} & \multirow{2}{*}{$\begin{array}{c}\text { EF } \\
\text { veh }\end{array}$} & \multirow{2}{*}{$\begin{array}{l}\text { ET } \\
\mathrm{h}\end{array}$} \\
\hline & & & & \\
\hline$A-C$ & A-a-c1-C & 1.2 & [68-73] & {$[0.25-0.28]$} \\
\hline A-C & A-e -d-C & 1.8 & [87-95] & {$[0.35-0.38]$} \\
\hline A-E & A-e-f-j-E & 2.2 & [118-126] & {$[0.45-0.50]$} \\
\hline$A-G$ & A-g-k-h-G & 2.8 & [137-146] & {$[0.50-0.55]$} \\
\hline$A-G$ & A-b-a-1-G & 1.4 & [78-83] & [0.30-0.33] \\
\hline
\end{tabular}

TSAEP: the starting and ending points.

ER: evacuation route.

P L: path length.

EF: evacuation flow.

ET: evacuation time. 
Table 3 Optimal Evacuation Routes of Ant Colony and Genetic Algorithm

\begin{tabular}{llccc}
\hline TSAEP & \multicolumn{1}{c}{ ER } & PL & EF & ET \\
& & $\mathrm{km}$ & $\mathrm{veh}$ & $\mathrm{h}$ \\
\hline A-C & A-b-c1-C & 1.1 & {$[68-73]$} & {$[0.24-0.27]$} \\
A-C & A-e-k-j-i-d-C & 2.3 & {$[87-95]$} & {$[0.30-0.35]$} \\
A-E & A-f-j-E & 0.8 & {$[118-126]$} & {$[0.25-0.35]$} \\
A-G & A-a-l-G & 1.4 & {$[137-146]$} & {$[0.35-0.40]$} \\
A-G & A-g-h-G & 1.2 & {$[78-83]$} & {$[0.28-0.33]$}
\end{tabular}

TSAEP: the starting and ending points.

ER: evacuation route.

P L: path length.

EF: evacuation flow.

ET: evacuation time.

The vehicle evacuation simulation is operated through Matlab for the above two algorithms. Comparison two algorithms, the evacuation time for using ant colony genetic algorithm is significantly lower than separate genetic algorithm through three vehicle evacuation. The simulation results verify the feasibility of vehicle emergency evacuation optimization algorithm in this paper.

\section{CONCLUSION}

The intention of the emergency evacuation is t transfer evacuated object to safe destination in the shortest possible time, not just confined to ensure the safety of persons, but also to ensure the security of personal property. With the improvement of living standards, more and more people pay attention to research the vehicle emergency evacuation. Though there are many details to be to explore and research, we hope this research can play a little help to the emergency evacuation problem.

\section{ACKNOWLEDGEMENTS}

This work was financially supported by National Nature Science Foundation (61203152), Program for Liaoning Excellent Talents in University (LNET) (LJQ2013122), Natural Science Foundation of Liaoning Province (Grant No. 2015020037) and General Project of the Education Department of Liaoning Province(L2014473).

\section{REFERENCES}

1) Ng M. W. \& Waller S. T. 2010. Reliable evacuation planning viadem and inflation and supply deflation. Transportation Research Part E: Logistics and Transportation Review 46(6): 10861094.

2) Waller S. T. \& Ziliaskopoulos A. K. 2006. A chance-constrained based stochastic dynamic traffic assignment model: analysis, formulation and solution algorithms. Transportation Research Part C: Emerging Technologies 14(6): 418-427.

3) Daniel H. 2010. Evaluating Local Government Emergency Management Programs: What Framework Should Public Manager Adopt. Public Administration Review (4): 236-246.

4) Jennifer W. \& Arthur O.Y. 2001. The evolution of emergency management and the advancement towards a profession in the United States and Florida. Safety Science 39: 117-131.

5) Helbing D \& Buzna L, Johansson A \&Werner T.2005. Self-Organized Pedestrain Crowd Dynamics: Experiments, Simulations and Design Solutions. Transportation Science 39 (1): 1-24.

6) Hobeika A G \& Changkyun K. 1998. Comparison of traffic assignments in evacuation modeling.Trans Power Syst 45: 192-198. 
7) Myung Y. S. \&Kim H. 2004. A cutting plane algorithm for computing k-edge survivability of a network. European Journal of Operation Research 156: 579 - 589.

8) Stepanov A \& Smith J M G. 2009 Multi-objective evacuation routing in transportation networks. European Journal of Operational Research 198(2): 435-446.

9) Cova T J \& Johnson J P. 2002 .Microsimulation of neighborhood evacuations in the urbanwildland interface. Environment and Planning A 34(12): 2211-2230.

10)Chen X. \& Zhan B. Agentbased modeling and simulation of urban evacuation: relative effectiveness of simultaneous and evacuation strategies. Transportation Research Board 04:0329.

11)Kwon E.\& Pitt S.2005.Evaluation of Emergency Evacuation Strategies for dow ntown event traffic using dynamic network model. 84th TRB Annual Meeting, Washington D C, January.

12)Han D. L. \&Yuan F. 2005.Evacuation modeling and operations using dynami c traffic assignment and most assignment and most desirable destination appro aches. The 84th Transportation Research Board Annual Meeting. Washington D C 964-969.

13)Pidd, M.,SilvaF.N.\& EgleseR.W.1996.A Simulation Model fbr Emei'gency Evacuat ion. European Journal of Operational Research 3:413-419. 